\title{
A metrology-based approach for measuring the social dimension of cognitive trust in collaborative networks
}

\author{
Javier Andrade-Garda ${ }^{1}$. Áurea Anguera ${ }^{2}$ - Juan Ares-Casal ${ }^{1} \cdot$ Rafael García-Vázquez $^{1}$ - Juan-Alfonso Lara ${ }^{3}$.D . \\ David Lizcano $^{3}$ · Santiago Rodríguez-Yáñez ${ }^{1}$. Sonia Suárez-Garaboa ${ }^{1}$
}

Received: 23 January 2018 / Accepted: 13 April 2018

(c) Springer-Verlag London Ltd., part of Springer Nature 2018

\begin{abstract}
This paper addresses the measurement of the social dimension of cognitive trust in collaborative networks. Trust indicators are typically measured and combined in literature in order to calculate partners' trustworthiness. When expressing the result of a measurement, some quantitative indication of the quality of the result-the uncertainty of measurement—should be given. However, currently this is not taken into account for the measurement of the social dimension of cognitive trust in collaborative networks. In view of this, an innovative metrology-based approach for the measurement of social cognitive trust indicators in collaborative networks is presented. Thus, a measurement result is always accompanied by its uncertainty of measurement, as well as by information traditionally used to properly interpret the results: the sample size, and the standard deviation of the sample.
\end{abstract}

Keywords Collaborative network $\cdot$ Measurement $\cdot$ Metrology $\cdot$ Social cognitive trust indicator $\cdot$ Uncertainty of measurement

Juan-Alfonso Lara

juanalfonso.lara@udima.es

$\bowtie$ Sonia Suárez-Garaboa

sonia.suarez@udc.es

Javier Andrade-Garda jag@udc.es

Áurea Anguera

aanguera@etsisi.upm.es

Juan Ares-Casal

juanar@udc.es

Rafael García-Vázquez

rafael@udc.es

David Lizcano

david.lizcano@udima.es

Santiago Rodríguez-Yáñez

santi@udc.es

1 Universidade da Coruña, Grupo ISLA, Dep. Computación, Fac. Informática, Elviña, 15071 A Coruña, Spain

2 Universidad Politécnica de Madrid, Carretera de Valencia Km 7, 28031 Madrid, Spain

3 Universidad a Distancia de Madrid, Vía de Servicio 15, 28400 Collado-Villalba, Spain

\section{Introduction}

Nowadays it is commonly accepted that, in a rapidly globalizing world, enterprises' structures and processes should evolve in order to deal with the globalization of the economy, the rapid growth of information technologies and the increase of competitiveness (García et al. 2016). In this context, the alliance of organizations is an essential mean for attending customers and business opportunities. This way, enterprise cooperation can be defined as an agreement between two, or more, independent enterprises that, not merging but joining or sharing some of their capabilities and/or resources, can establish some kind of interrelation to increase their competitive advantages (Andrade et al. 2015). Thanks to the advance of the information and communications technologies (ICTs), such cooperation could take the form of a collaborative network $(\mathrm{CN})$.

Following Camarinha-Matos and Afsarmanesh (2005), a $\mathrm{CN}$ is constituted by a variety of entities (e.g., organizations and people) that are largely autonomous, geographically distributed, and heterogeneous in terms of their operating environment, culture, social capital, and goals. In order to achieve common or compatible goals, these entities collaborate and interact using computer networks. In CNs, 